\title{
Development of Monolithic Materials with and without a Binder with Carbon Molecular Sieving Properties
}

\author{
J.M. Valente Nabaisa, A. Padre-Eternob, P.J.M. Carrottc, \\ M.M.L. Ribeiro Carrottd, C. Galachoe \\ Universidade de Évora, Centro de Química de Évora \& Departamento de Química, \\ Rua Romão Ramalho n59, 7000-671 Évora, Portugal \\ ajvn@uevora.pt, bana.eterno@portugalmail.pt, cpeter@uevora.pt, dmanrc@uevora.pt, \\ epcg@uevora.pt
}

Keywords: Carbon Materials, Gas Separation, Acrylic Textile Fibre.

Abstract. In this work we studied the production of activated carbon fibres in monolith shape from a commercial textile acrylic fibre. The monoliths were produced with and without a binder. The binders tested were phenolic resin, polystyrene, polymethylmethacrylate and clay. We also tested the influence of using a solvent. The SEM analysis indicates that the monoliths are made of filaments that can be considered activated carbon fibres. The type of binder influences the fibre orientation, degradation and materials shrinkage, the worst results being obtained from the use of polymethylmethacrylate and polystyrene in toluene. The best results are obtained when the monoliths were produced only with acrylic fibre and with phenolic resin as binder. The use of solvents has opposite effects for the carbonised and activated samples. In the former case it seems that the water can be fibre protective but during activation the presence of water leads to an increase in the monolith's burn-off. The methodology used leads to the formation of excellent samples for performing the gas separations $\mathrm{O}_{2} / \mathrm{N}_{2}$ and $\mathrm{CO}_{2} / \mathrm{CH}_{4}$. Some samples show maximum selectivity for the referred separations because $\mathrm{N}_{2}$ and $\mathrm{CH}_{4}$ are almost totally excluded from the porous structure which indicates a good potential to be utilised in PSA systems or for natural gas purification. The adsorption capacity is very dependent on the conditions used. Nevertheless, the best sample has a considerably high adsorption capacity $\left(32 \mathrm{~cm}_{3} \mathrm{~g}-1\right.$ for $\mathrm{CO}_{2}$ and $4 \mathrm{~cm}_{3} \mathrm{~g}-1$ for $\mathrm{O}_{2}$, after $200 \mathrm{~s}$ contact time). 